\title{
Hourly wages of physicians within medical fees based on the Korean relative value unit system
}

\author{
Hyun Ah Kim ${ }^{1}$, Sung Hoon Jung ${ }^{2}$, In Young Park ${ }^{1}$, and Seong Hun Kang
}

${ }^{1}$ Department of Internal Medicine, Hallym University Sacred Heart Hospital, Anyang; ${ }^{2}$ Department of Internal Medicine, St. Paul's Hospital, College of Medicine, The Catholic University of Korea, Seoul, Korea

Received: December 14, 2018

Revised : March 4, 2019

Accepted: March 15, 2019

\section{Correspondence to}

Hyun Ah Kim, M.D.

Division of Rheumatology,

Department of Internal

Medicine, Hallym University

Sacred Heart Hospital, 22

Gwanpyeong-ro 17obeon-gil,

Dongan-gu, Anyang 14068, Korea

Tel: $+82-31-380-1826$

Fax: $+82-31-381-8812$

E-mail: kimha@hallym.ac.kr
Background/Aims: It is difficult to reach a social agreement on the appropriate level of compensation for professionals. This study was performed to examine the physician fee embedded in the relative value unit (RVU) system in comparison with the Korean hourly minimum wage.

Methods: The Health Insurance Service Price and the Korean Classification of Procedural Terminology were used to obtain the hourly wages of physicians for designated health care services. In addition, the physician fee schedule at the United States Centers for Medicare and Medicaid Services and the Organisation for Economic Co-operation and Development (OECD) report on minimal wage were used. Health care service fees were selected based on laboratory, pathology, imaging, and procedure codes as well as examination fees. For calculation of physician labor costs per hour, physician workload $\times$ conversion factor was divided by the time involved. To calculate the proportion of physician labor fee in the total fee, the physician workload RVU for each service fee was divided by the total RVU. Results: A total of 27 physician fee codes were selected. Compared to the Korean hourly minimum wage in 2015 , the average physician wages were greater by $2.80-$ fold for primary care and by 3.05-fold for tertiary care. The mean proportion of physician labor cost in the total cost was 0.19 , which was significantly lower than that of corresponding procedures in the United States RVU (mean, 0.48).

Conclusions: The average Korean physician wages compared to the hourly minimum wage were disproportionately low compared to the USA and other reference OECD countries.

Keywords: Physician; Medical fee

\section{INTRODUCTION}

South Korea introduced the National Health Insurance (NHI) system in 1977 and set up coverage for the entire Korean population within a very short time by 1989. In South Korea, waiting times for various medical diagnoses and treatments are short, and the quality of medical care is good [1]. South Koreans' health status has improved rapidly during this period, and life expectancy at birth rose from 64.4 years in 1976 to 79.1 years in 2006 [2].
At the time of introduction of the Korean NHI system in 1977, the economic level of the country was low, with a gross domestic product of $\$ 1,000$ United States dollars per capita. Implementation of the NHI was possible because of the low physician fee schedule, which was set at $55 \%$ to $75 \%$ of the cost of services at that time [3]. In contrast to Western countries where health insurance is a product of a welfare-related social agreement, the Korean NHI system was part of the 5-year Economic Development Plans, under the military authoritarian gov- 
ernment, which aimed to increase the people's support base to maintain the regime. As the NHI was available to less than $10 \%$ of the population at the time of its inception, physicians underestimated its effect and tolerated the low fee level. Expansion of the Korean NHI system was promoted not only by rapid economic growth but also by the political agenda of military presidents following the Park Chunghee regime as a way to gain support and legitimacy. Increases in public expenditure and the contribution rate of payroll income $5.64 \%$ of payroll income in 2011) were not taken into consideration for political reasons. In particular, proper reimbursement of physicians was an unpopular policy, and physician's fees remained low long after universal coverage was achieved. This situation kept public expenditure as a proportion of total health expenditure low (55.3\%), compared to an average of $72.5 \%$ among member countries of the Organisation for Economic Co-operation and Development (OECD) [1]. On the patient side, low benefit coverage and increases in out-of-pocket expenses led to a decrease in patient satisfaction rate, with only $49.2 \%$ of those insured reporting being satisfied with the NHI system $[4,5]$. On the provider side, under-compensation of physicians for their services resulted in physicians decreasing their service time and pursuing imaging and laboratory-based practices, which are better compensated than physician services, as well as disproportionately moving into specialties that are not covered by NHI, such as dermatology and plastic surgery.

One study indicated an extremely low level of overall job satisfaction among Korean physicians, with only $33.2 \%$ of physicians reporting satisfaction [6]. The low physician fees that force physicians to pursue high-volume clinical care is directly related to inadequate time spent with patients and an inability to maintain ongoing relationships with patients, which are known to be significantly associated with physician dissatisfaction $[7,8]$. This is a matter of great concern because physicians' job dissatisfaction contributes to reduced quality of care, and adversely affect health outcomes [9]. Therefore, it is important to determine an appropriate compensation level so that physicians can secure sufficient time for good practice. It is always difficult to achieve social agreement regarding an appropriate level of compensation for professionals who are considered to provide services important for public welfare, such as physi- cians. One way to tackle this issue would be to compare physician compensation with the national minimal wage, which forms a foundation of the social contract in terms of wages and work compensation.

This study was performed to examine the physician fees embedded in the Korean relative value unit (RVU) system, which determines physician fees for various health care services, in comparison with the Korean hourly minimum wage. In addition, the proportion of physician fees within the total fees was compared to that in the USA.

\section{METHODS}

\section{Data source}

The Health Insurance Service Price (7th version) and the Korean Classification of Procedural Terminology were used to determine the physician hourly wage for designated health care services [10]. The physician fee schedule of the United States Centers for Medicare and Medicaid Services (CMS) [11] website was used to obtain data from the USA. The OECD report was used to obtain information on hourly minimum wage [12].

According to Korean Health Insurance Service Price system, hospitals are classified as follows, hospital: more than 30 beds, general hospital: more than 100 beds, tertiary hospital: hospitals that provides health care from specialists in a large hospital after referral from primary care and secondary care. This study used data which do not contain information on human subjects and which are available on public website. Institutional Review Board (IRB) approval is not needed in such studies according to Hallym University Sacred Hospital IRB.

\section{Selection of health care service fee}

Health care service fees for analysis were selected from the laboratory, pathology, imaging, and procedure codes, as well as examination fees. Surgical codes were excluded from the analysis. The following codes were selected for laboratory and pathological examinations: bone marrow aspirate smear examination, potassium hydroxide $(\mathrm{KOH})$ mount for fungus examination, polarizing microscopy, Pap smear, cell block examination, and frozen section pathology. For imaging examinations, the following codes were selected: chest postero-ante- 
rior, chest high-resolution computed tomography (CT), brain magnetic resonance imaging (MRI), and bone scan. The following codes for procedures were selected: gastrofiberscopy, colonofiberscopy, endoscopic polypectomy, electromyography, electroencephalography, coronary angiography, electrophysiological study including His-bundle examination, joint aspiration, bone marrow aspiration and biopsy, thoracentesis, paracentesis, peritoneal biopsy, and pleural biopsy. Neurological examination fee, brain death evaluation fee, dementia evaluation fee, including global deterioration scale and clinical dementia rating were also included.

\section{Calculation of physician fee}

The service fee according to the Korean RVU was determined as fee $=$ relative value unit $\times$ conversion factor, and the RVU was determined as physician workload + practice expense + equipment cost value + material cost value. Physician workload was determined by the time involved and the risk value. To calculate the physician labor cost per hour, the physician workload $\times$ conversion factor was divided by time involved for each service fee based on the Korean Classification of Procedural Terminology.

\section{Calculation of the proportion of the physician fee in the total fee}

To calculate the proportion of the physician labor fee in the total fee, the physician workload RVU for each service fee was divided by the total RVU. For comparison with the proportion of the physician labor fee in the USA, the workload RVU was divided by the total RVU according to the data provided by the United States Medicare Fee for Service Payment database.

\section{RESULTS}

A total of 29 physician fee codes were selected. The hourly physician fees for designated laboratory services are listed in the Table 1 and ranged from 378 Korean won (KW) for a fungus $\mathrm{KOH}$ mount to $27,308 \mathrm{KW}$ for frozen section pathological examinations for primary care. Tertiary care physician fees ranged from $411 \mathrm{KW}$ to $29,743 \mathrm{KW}$. For imaging examination, the hourly physician fees for primary care ranged from 11,083 KW for a bone scan reading to 31,610 KW for a brain MRI reading. For tertiary care, the corresponding hourly physician fees were 12,072 and 34,429 KW, respectively. Fees for endoscopy, aspiration, biopsy, interventional cardiology services, and other procedures are shown in the Table 1. The fees ranged from 8,079 KW for bone marrow aspiration to $38,557 \mathrm{KW}$ for an electrophysiological study for primary care. The corresponding hourly fees were 8,799 and 42,017 KW, respectively for tertiary care. For neurological examinations, the hourly physician fees were 9,040 KW for primary care and 9,846 KW for tertiary care. Other neurology fees ranged from 10,366 KW to $16,414 \mathrm{KW}$ for primary care and 11,290 to 17,878 for tertiary care, respectively. Compared to the Korean hourly minimum wage in $2015(5,580 \mathrm{KW})$, the average physician wages were greater by 2.80 -fold for primary care and by 3.05 -fold for tertiary care. The proportion of the physician labor cost in the total cost ranged from 0.01 for a fungus $\mathrm{KOH}$ mount to 0.49 for a brain death evaluation (Fig. 1). The mean value was 0.19 (standard deviation, 0.09). For comparison, the mean proportion of the physician labor cost in the total cost for the corresponding procedures in the USA RVU was 0.48 (standard deviation, 0.19).

\section{DISCUSSION}

In this study, the average physician wages ranged from 2.80-fold (primary care) to 3.05-fold (tertiary care) higher than the hourly minimum wage. Compared to physician wages in the USA, the proportion of physician labor cost within the total cost was significantly lower in Korea, accounting for only $19 \%$ of the total cost.

Physician fees in Korea are determined by the RVU system, which was largely adapted from the system used in the USA. RVUs are part of the resource-based relative value scale (RBRVS), which was designed to value physician services and to serve as a guide for reimbursement [13]. The United States RVU started with the introduction of the Medicare fee schedule, which was developed because of problems of wide-ranging differences in payments for the same service, which did not reflect the quality of these services or their value to patients. A large study was conducted to evaluate the relative amounts of physicians' work, which took into 
Table 1. Hourly physician wages for various procedures and examinations

\begin{tabular}{|c|c|c|c|c|c|c|c|c|}
\hline \multirow{2}{*}{ Item } & \multicolumn{4}{|c|}{ Hourly wages (Korean won) } & \multicolumn{4}{|c|}{$\begin{array}{l}\text { Hourly physician wage divided by hourly } \\
\text { minimum wage }\end{array}$} \\
\hline & Clinic & Hospital & $\begin{array}{l}\text { General } \\
\text { hospital }\end{array}$ & $\begin{array}{l}\text { Tertiary } \\
\text { hospital }\end{array}$ & Clinic & Hospital & $\begin{array}{l}\text { General } \\
\text { hospital }\end{array}$ & $\begin{array}{l}\text { Tertiary } \\
\text { hospital }\end{array}$ \\
\hline \multicolumn{9}{|c|}{ Laboratory and pathological examination } \\
\hline $\begin{array}{l}\text { Bone marrow smear } \\
\text { reading }\end{array}$ & $13,439.0$ & $13,511.5$ & $14,074 \cdot 5$ & $14,637 \cdot 5$ & 2.41 & 2.42 & 2.52 & 2.62 \\
\hline Cell block Examination & $18,109.0$ & $18,206.7$ & $18,965.4$ & $19,724.0$ & 3.25 & 3.26 & 3.40 & $3 \cdot 53$ \\
\hline $\begin{array}{l}\text { Nail KOH mount } \\
\text { fungus exam }\end{array}$ & 378.1 & 380.2 & 396.0 & 411.8 & 0.07 & 0.07 & 0.07 & 0.07 \\
\hline $\begin{array}{l}\text { Frozen biopsy reading } \\
\text { during operation }\end{array}$ & $27,308.4$ & $27,455.8$ & $28,599.8$ & $29,743 \cdot 7$ & 4.89 & 4.92 & 5.13 & $5 \cdot 33$ \\
\hline Polarizing mcroscopy & $3,639 \cdot 4$ & $3,659.0$ & $3,811.5$ & 3,964 & 0.65 & 0.66 & 0.68 & 0.71 \\
\hline Pap smear & $9,285.8$ & $9,335 \cdot 9$ & $9,724.8$ & $10,113.8$ & 1.66 & 1.67 & 1.74 & 1.81 \\
\hline \multicolumn{9}{|l|}{ Imaging examinations } \\
\hline Simple chest X-ray & $23,711.3$ & $23,839.2$ & $24,832.5$ & $25,825.8$ & 4.25 & 4.27 & $4 \cdot 45$ & 4.63 \\
\hline Chest high-resolution CT & $15,427 \cdot 3$ & $15,510.5$ & $16,156.8$ & $16,803.1$ & 2.76 & 2.78 & 2.90 & 3.01 \\
\hline Brain MRI & $31,610.8$ & $31,781.4$ & $33,105 \cdot 6$ & $34,429.8$ & 5.67 & 5.70 & 5.93 & 6.17 \\
\hline Bone scan & $11,083.6$ & $11,143 \cdot 4$ & $11,607.8$ & $12,072.1$ & 1.99 & 2.00 & 2.08 & 2.16 \\
\hline \multicolumn{9}{|l|}{ Endoscopy } \\
\hline Gastrofiberscope & $32,256.0$ & $32,430.0$ & $33,781.2$ & $35,132.5$ & $5 \cdot 78$ & 5.81 & 6.05 & 6.30 \\
\hline Colonofiberscope & $21,523 \cdot 6$ & $21,639 \cdot 7$ & $22,541.4$ & $23,443.1$ & 3.86 & 3.88 & 4.04 & 4.20 \\
\hline Polypectomy & $31,963.0$ & $32,135 \cdot 4$ & $33,474 \cdot 4$ & $34,813 \cdot 4$ & 5.73 & 5.76 & 6.00 & 6.24 \\
\hline \multicolumn{9}{|l|}{ Other procedures } \\
\hline $\begin{array}{l}\text { His bundle } \\
\text { electrophysiology }\end{array}$ & $38,577 \cdot 7$ & $38,785.8$ & $40,401.9$ & $42,018.0$ & 6.91 & 6.95 & 7.24 & $7 \cdot 53$ \\
\hline Coronary angiography & $15,102.5$ & $15,184.0$ & $15,816.7$ & $16,449 \cdot 3$ & 2.71 & 2.72 & 2.83 & 2.95 \\
\hline Arthrocentesis & $30,034 \cdot 3$ & $30,196.3$ & $31,454 \cdot 5$ & $32,712.7$ & $5 \cdot 38$ & $5 \cdot 41$ & 5.64 & 5.86 \\
\hline Thoracentesis & $11,485 \cdot 4$ & $11,547 \cdot 4$ & $12,028.5$ & $12,509.6$ & 2.06 & 2.07 & 2.16 & 2.24 \\
\hline Paracentesis & $10,475 \cdot 5$ & $10,532.0$ & $10,970.9$ & $11,409.7$ & 1.88 & 1.89 & 1.97 & 2.04 \\
\hline Peritoneal biopsy & $16,423.0$ & $16,511.6$ & $17,199.6$ & $17,887.6$ & 2.94 & 2.96 & 3.08 & 3.21 \\
\hline Pleural biopsy & $14,076.9$ & $14,152.8$ & $14,742.5$ & $15,332.2$ & 2.52 & 2.54 & 2.64 & 2.75 \\
\hline $\begin{array}{l}\text { Bone marrow aspiration } \\
\text { biopsy }\end{array}$ & $10,772.9$ & $10,831.0$ & $11,282.3$ & $11,733.6$ & 1.93 & 1.94 & 2.02 & 2.10 \\
\hline Bone marrow aspiration & $8,079.2$ & $8,122.8$ & $8,461.2$ & $8,799 \cdot 7$ & 1.45 & 1.46 & 1.52 & 1.58 \\
\hline \multicolumn{9}{|l|}{ Neurological examinations } \\
\hline General neurologic exam & $9,040.2$ & $9,089.0$ & $9,467.7$ & $9,846.4$ & 1.62 & 1.63 & 1.70 & 1.76 \\
\hline $\begin{array}{l}\text { Neurologic exam for } \\
\text { brain death }\end{array}$ & $15,139 \cdot 5$ & $15,221.2$ & $15,855 \cdot 4$ & $16,489 \cdot 6$ & 2.71 & 2.73 & 2.84 & 2.96 \\
\hline Dementia test & $10,366.2$ & $10,422.2$ & $10,856.4$ & $11,290.7$ & 1.86 & 1.87 & 1.95 & 2.02 \\
\hline Electromyography & $16,414.2$ & $16,502.7$ & $17,190.4$ & $17,878.0$ & 2.94 & 2.96 & 3.08 & 3.20 \\
\hline $\begin{array}{l}\text { Awake } \\
\text { electroencephalogram }\end{array}$ & $14,511.7$ & $14,590.0$ & $15,197 \cdot 9$ & $15,805.8$ & 2.60 & 2.61 & 2.72 & 2.83 \\
\hline
\end{tabular}




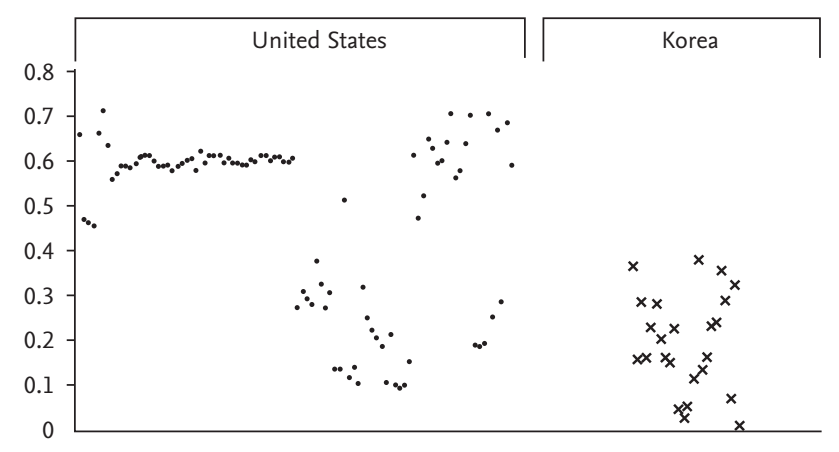

Figure 1. The distribution of the proportion of physician labor fee in the total fee.

account the physician's time, mental effort, judgment, technical skill, physical effort, and psychological stress [14]. The study was published in 1988, and used as the basis for the Omnibus Budget Reconciliation Act, which implemented the RBRVS fee schedule effective January 1992 [15]. At present, physician reimbursement from the United States CMS is determined by the service indicated by the current procedural terminology code, each of which carries a corresponding RVU. The payment formula consists of three RVUs: physician work accounting for the physician's time, skill, training, and intensity of work that contributed to the service; practice expense, accounting for expenses including rent, equipment, supplies, and non-physician staff costs; and professional liability insurance expenses.

At the beginning of the Korean NHI system in 1977, the physician fee was loosely based on the Japanese fee system. In 2001, the RVU, employing the United States RBRVU system, was first introduced, and payment was determined by physician workload and practice expense. However, political adjustment of the RBRVS in 1997 weakened the relationship between the relative value scale and resource consumption [16]. Instead of analyzing the real-world situation and nationwide cost data, the government used data from only eight hospitals and determined physician fees by multiplying by a fixed value automatically. Therefore, the Korean RVU did not adequately embody the physicians' workload, let alone revise the low fees, which had been responsible for the distortion of medical practices. A research project for revision of the RBRVS began, and physician work, practice expense, and malpractice fee were divided. The practice expense relative value composed of labor costs for assisting physicians, nurses, and medical technicians, material costs, and equipment costs was set for each medical procedure. However, as the final relative values were set with the principle of budget neutrality, which meant that the total relative value score of a department remained the same after revision, the purpose of generating "resource based" relative value scales largely failed. The problem of non-separation of physician work and practice expenses was never solved.

Proper physician compensation is important in every aspect of health care because physicians influence the medical practice to a greater degree that other health-related professionals. A study of physicians and medical group leaders representing 46 medical group practices in the United States reported that financial incentives do affect a variety of physician behaviors such as time spent with patients or volume of diagnostic services ordered [17]. Under-compensation for physician congnitive service is problematic considering the ever-increasing complexity of current day patients. Despite health care reforms in the United States focus on preventive care and quality measures that rely on a strong base of primary care physicians, fewer United States medical graduates are entering primary care practices [18]. A study showed that primary care physicians have expenses that exceed earnings early in career, which creates great financial disincentive for pursuing a career in primary care compared with other fields of medicine better compensated [19]. A recent study showed that there are significant international variations in physician consultation length [20]. It was found out that a large proportion of the global population have only a few minutes with their primary care physicians, which was concerning since a short consultation length is likely to adversely affect patient healthcare and physician workload. Unfortunately, Korean health care is criticized by short consultation time, which seriously aggravates quality of care and physician stress. Considering under-compensation in time spent by physician, it would be very difficult to change this practice. However, there is a paucity of data regarding on what constitutes an appropriate level of physician compensation, even in developed countries. In this study, we calculated physician wages reflected in the Korean RVU in comparison with the Korean hourly minimum wage in 2015. The results indicated that Korean physician fees are on average 2.8-3-fold higher 
than the minimum wage. As a reference, physician consultation fees for United States Medicare and Medicaid, which defines a minimum flat physician fee publicly, are on average greater than the minimum wage by $22.4^{-}$ fold for new patients and 22.9-fold for established patients [11]. In Australia, the physician consultation fees are on average 9.2-fold higher than minimum wage, while in Germany and France, 9.8- fold higher [21-23]. How much a physician should be compensated in the context of other constituents of the society is a complicated issue that must be negotiated socially. However, it is clear that the Korean system of RVU compensates physician labor very poorly compared to other reference countries. It is essential that a civilized society come to an agreement on the level of compensation for a profession that is responsible for proper utilization of crucial public resources, such as health care. Inappropriate compensation would lead to distortion of practices that overly depend on better compensated procedures (in Korea, laboratory and imaging examinations) and avoidance of necessary services, which will inevitably lead to low quality of care and a waste of resources.

The separation of physician workload and practice expense is another basic requirement to prevent the inappropriate utilization of health care resources. By paying physicians separate fees that are not linked to the facility, the independence and autonomy of physician practice can be better supported. Our study showed that not only is the physician fee not separately paid in Korea, but the proportion of the physician fee within the total fee is markedly lower than in the USA. This would lead to a system of exploitation of physicians on behalf of health care administration in a way that physicians are coerced into making the most profit instead of bringing the best value to patients.

Our study had some limitations. The Korean relative value system is not based on a proper analysis of cost data and poorly reflects resource consumption. To compensate for the extremely low physician labor cost, the RVU has been distorted by inflating the physician time, which makes a sound comparison with hourly minimum wage very difficult. Examining the current RVU, however, would provide insight on how it should be revised. Fees for surgical procedures were not included because of heterogeneity and complexity in setting their relative value. Finally, due to the recent increase in the
Korean minimum wage from 5,580 to 8,350 KW between 2015 to 2019 without a corresponding increase in medical fees, our analysis may still have overestimated physician labor cost compared to the hourly minimum wage.

In conclusion, the average physician compensation relative to the hourly minimum wage in Korea was determined to be disproportionately low compared to that in the USA and other reference OECD countries. To increase the quality of patient care and achieve the best value for patients, proper compensation of physicians for their endeavors instead of for laboratory and imaging examinations is required.

\section{KEY MESSAGE}

1. Compared to the Korean hourly minimum wage in 2015, the average physician wages were greater by 2.80 -fold for primary care and by 3.05-fold for tertiary care.

2. The mean proportion of physician labor cost in the total cost was 0.19 , which was significantly lower than that of corresponding procedures in the United States relative value unit.

\section{Conflict of interest}

No potential conflict of interest relevant to this article was reported.

\section{Acknowledgments}

This research was supported by a grant of the Korea Health Technology R\&D Project through the Korea Health Industry Development Institute (KHIDI),funded by the Ministry of Health and Welfare, Republic of Korea (grant number: HI15C2699) and by the Hallym University Research Fund.

\section{REFERENCES}

1. Kang MS, Jang HS, Lee M, Park EC. Sustainability of Korean National Health Insurance. J Korean Med Sci 2012;27 Suppl:S21-S24.

2. Jeong HS. Korea's National Health Insurance: lessons from the past three decades. Health Aff (Millwood) 2011;30:136144 . 
3. Kwon S. Thirty years of national health insurance in South Korea: lessons for achieving universal health care coverage. Health Policy Plan 2009;24:63-71.

4. Flynn ML, Chung YS. Health care financing in Korea: private market dilemmas for a developing nation. J Public Health Policy 1990;11:238-253.

5. Soe SR, Choi ID, Moon SW, Kim JS, Hwang RI. Satisfaction survey of national health insurance, 2008. Wonju (KR): National Health Insurance Corporation, 2008.

6. Lee HY, Park SE, Park EC, Hahm MI, Cho WH. Job satisfaction and trust in Health Insurance Review Agency among Korean physicians. Health Policy 2008;87:249-257.

7. DeVoe J, Fryer Jr GE, Hargraves JL, Phillips RL, Green LA. Does career dissatisfaction affect the ability of family physicians to deliver high-quality patient care? J Fam Pract 2002;51:223-228.

8. Haas JS. Physician discontent: a barometer of change and need for intervention. J Gen Intern Med 2001;16:496-497.

9. Zuger A. Dissatisfaction with medical practice. N Engl J Med 2004;350:69-75.

10. Korean Medical Association. The Korean Classification of Procedural Terminology 2017 [Internet]. Seoul (KR): Korean Medical Association, c2017 [cited 2019 Oct 16]. Available from: http://kcpt.kma.org/.

11. Centers for Medicare \& Medicaid Services. Physician Free Schedule 2017 [Internet]. Baltimore (MD): Centers for Medicare \& Medicaid Services, 2018 [cited 2019 Oct 16]. Available from: https://www.cms.gov/Medicare/MedicareFee-for-Service-ayment/PhysicianFeeSched/PFS-FederalRegulation-Notices-Items/CMS-1654-F.html.

12. Organisation for Economic Co-operation and Development. Real minimum wages 2017 [Internet]. Paris (FR): Organisation for Economic Co-operation and Development, c2019 [cited 2019 Oct 16]. Available from: https://stats.oecd.org/Index.aspx?DataSet Code=RMW.

13. Baadh A, Peterkin Y, Wegener M, Flug J, Katz D, Hoffmann
JC. The relative value unit: history, current use, and controversies. Curr Probl Diagn Radiol 2016;45:128-132.

14. Hsiao WC, Braun P, Dunn D, Becker ER. Resource-based relative values: an overview. JAMA 1988;260:2347-2353.

15. Beck DE, Margolin DA. Physician coding and reimbursement. Ochsner J 2007;7:8-15.

16. Kang GW, Lee CS. The refinement project of health insurance relative value scales: results and limits. Korean J Health Policy Adm 2007;17:1-25.

17. Tufano J, Conrad DA, Sales A, et al. Effects of compensation method on physician behaviors. Am J Manag Care 2001;7:363-373.

18. Ebell MH. Future salary and US residency fill rate revisited. JAMA 2008;300:1131-1132.

19. Palmeri M, Pipas C, Wadsworth E, Zubkoff M. Economic impact of a primary care career: a harsh reality for medical students and the nation. Acad Med 2010;85:1692-1697.

20. Irving $\mathrm{G}$, Neves $\mathrm{AL}$, Dambha-Miller $\mathrm{H}$, et al. International variations in primary care physician consultation time: a systematic review of 67 countries. BMJ Open 2017;7:e017902.

21. Commonwealth of Australia. Medicare Benefits Schedule. [Internet]. Canberra (AU): Commonwealth of Australia, c2018 [cited 2019 Oct 16]. Available from: http://www. mbsonline.gov.au/internet/mbsonline/publishing.nsf/ Content/Home.

22. Kassenarztliche Bundesvereinigung. Bundesarztregister [Internet]. Berlin (DE): Kassenarztliche Bundesvereinigung, c2018 [cited 2019 Oct 16]. Available from: https://www.kbv. de/html/index.php.

23. Caisse nationale de l'assurance maladie. Classification commune des actes médicaux [Internet]. Paris (FR): Caisse nationale de l'assurance maladie, 2019 [cited 2019 Oct 16]. Available from: https://assurance-maladie.ameli.fr/quisommes-nous/fonctionnement/organisation/cnam-tetereseau. 